\title{
Deep Cerebral Venous Thrombosis-A Clinicoradiological Study
}

\author{
Sujana Gogineni ${ }^{1}$ Dhananjay Gupta ${ }^{1} \quad$ R. Pradeep ${ }^{1} \quad$ Anish Mehta $^{1}$ Mahendra Javali ${ }^{1}$ \\ Purshottam T. Acharya ${ }^{1}$ Rangasetty Srinivasa ${ }^{1}$
}

${ }^{1}$ Department of Neurology, Ramaiah Medical College, Bengaluru, India

\begin{abstract}
Address for correspondence Pradeep R., MD, DM, Department of Neurology, Ramaiah Medical College and Hospitals, Bengaluru 560054, India (e-mail: drrajipradeep@gmail.com).
\end{abstract}

J Neurosci Rural Pract 2021;12:560-565.

\begin{abstract}
Keywords

- acute stroke treatment

- cerebral venous thrombosis

- cerebrovascular disease

- neuroimaging

- stroke

Stroke is a common neurological emergency. Almost $80 \%$ of strokes are due to arterial occlusion. Venous thrombosis comprises less than $1-2 \%$ of all strokes. Involvement of the deep cerebral venous system is still rare and accounts for about $10.9 \%$ of all cerebral venous thromboses (CVT). CVT diagnosis is often delayed or missed, because of its variable clinical manifestations. We retrospectively (2015-18) and prospectively (201820 ) reviewed all the cases of CVT in a tertiary care center in south India. Out of a total of 52 CVT cases, 12 were due to the involvement of deep cerebral venous system. Their clinical presentation, imaging characteristics, and outcomes were assessed. The most frequent presentation was headache followed by seizures. Hyperhomocysteinemia was the most common risk factor noted. Imaging characteristics were variable, and a high index of suspicion was required for early diagnosis. All patients had favorable outcome in our study, and except one, all were treated conservatively.
\end{abstract}

\section{Introduction}

Cerebral venous thrombosis (CVT) is an uncommon cause of cerebrovascular disease and accounts for about 0.5 to $1 \%$ of all strokes. ${ }^{1}$ The prevalence of CVT is 5 per 1 million adults and it is more common in women. ${ }^{2-4}$ Approximately $5 \%$ cases of stroke in young occur due to CVT. ${ }^{5}$ Involvement of deep cerebral venous system is rare, and accounts for just $10.9 \%$ of all CVT cases. ${ }^{3}$ Most of our current knowledge about deep CVT is through isolated case reports or small case series. There is a paucity of data from the Indian subcontinent in particular. CVT diagnosis is often delayed or missed, given its variable clinical manifestations, and it can mimic other acute neurological conditions. This delay can be avoided by optimal and timely brain imaging. ${ }^{6}$ CVT in general has a favorable prognosis, if diagnosed and treated early. ${ }^{7}$ This study is one of

published online June 16, 2021
DOI https://doi.org/ 10.1055/s-0041-1730109 ISSN 0976-3147 the first of its kind in India and was done in view of paucity of data about deep cerebral venous system thrombosis in the Indian subcontinent.

\section{Materials and Methods}

The study was started in January 2018 at a tertiary care center in south India. All patients diagnosed with CVT from January 2015 to January 2018 were reviewed retrospectively to identify those with deep CVT. From January 2018 to June 2020, all CVT cases were analyzed prospectively. The aim of this study was to study the clinical manifestations and radiological features of patients with deep CVT. The objectives of the study were to look for etiology, signs and symptoms, and outcomes of deep CVT. A total of 12 patients were diagnosed to have CVT due to involvement of deep cerebral venous system.

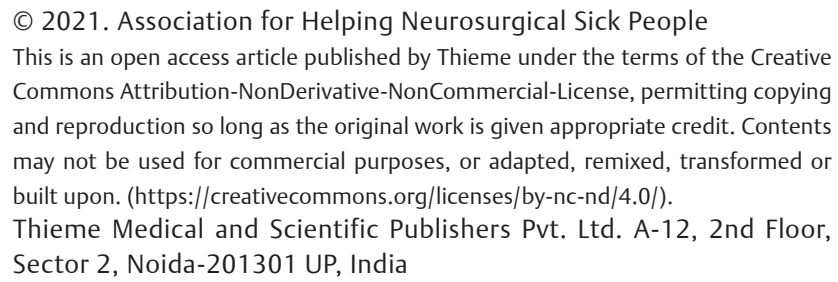
and reproduction so long as the original work is given appropriate credit. Contents may not be used for commercial purposes, or adapted, remixed, transformed or built upon. (https://creativecommons.org/licenses/by-nc-nd/4.0/).

Thieme Medical and Scientific Publishers Pvt. Ltd. A-12, 2nd Floor, Sector 2, Noida-201301 UP, India 
Table 1 Clinical and radiological features

\begin{tabular}{|c|c|c|c|c|c|}
\hline S. No & $\begin{array}{l}\text { Age } \\
\text { (years) }\end{array}$ & Gender & Clinical presentation & Veins involved & MRI features \\
\hline 1. & 32 & Female & $\begin{array}{l}\text { Headache, vomiting, } \\
\text { blurring of vision, altered } \\
\text { sensorium }\end{array}$ & $\begin{array}{l}\text { Internal cerebral vein, } \\
\text { right transverse sinus }\end{array}$ & $\begin{array}{l}\text { Thalamus, left internal capsule, left } \\
\text { basal ganglia, right caudate, right } \\
\text { cerebellar hemorrhagic infarcts }\end{array}$ \\
\hline 2. & 30 & Male & Headache, vomiting & $\begin{array}{l}\text { Vein of Galen, internal cerebral } \\
\text { vein, right transverse sinus, } \\
\text { straight sinus }\end{array}$ & $\begin{array}{l}\text { Bilateral thalamus infarction with } \\
\text { hemorrhage in right thalamus }\end{array}$ \\
\hline 3. & 53 & Male & Headache, vomiting & $\begin{array}{l}\text { Vein of Galen, straight sinus, } \\
\text { right transverse, sigmoid } \\
\text { sinus, internal jugular vein }\end{array}$ & Bilateral cerebellar hemorrhage \\
\hline 4. & 22 & Male & Headache & $\begin{array}{l}\text { Superior sagittal sinus, right } \\
\text { transverse, sigmoid, straight } \\
\text { sinus thrombosis, vein of } \\
\text { Galen }\end{array}$ & $\begin{array}{l}\text { Right temporal lobe hemorrhagic } \\
\text { infarct }\end{array}$ \\
\hline 5. & 21 & Male & Headache, Seizures & $\begin{array}{l}\text { Internal cerebral veins, inferior } \\
\text { sagittal sinus, transverse sinus, } \\
\text { sigmoid, straight sinus }\end{array}$ & $\begin{array}{l}\text { Bilateral frontal, left thalamus, basal } \\
\text { ganglia, left occipital hemorrhagic } \\
\text { infarcts }\end{array}$ \\
\hline 6. & 30 & Female & $\begin{array}{l}\text { Headache, Blurring of } \\
\text { vision }\end{array}$ & $\begin{array}{l}\text { Vein of Galen, inferior sagittal } \\
\text { sinus, straight sinus, bilateral } \\
\text { transverse sinus }\end{array}$ & $\begin{array}{l}\text { Right temporal hematoma, callosal, } \\
\text { basal ganglia hemorrhagic infarcts }\end{array}$ \\
\hline 7. & 23 & Female & Headache & $\begin{array}{l}\text { Vein of Galen, straight sinus, } \\
\text { bilateral transverse, sigmoid } \\
\text { sinus }\end{array}$ & Left temporal venous infarct \\
\hline 8. & 26 & Male & Headache, seizures & $\begin{array}{l}\text { Basal vein of Rosenthal, } \\
\text { internal cerebral vein, vein } \\
\text { of Galen, straight sinus, left } \\
\text { transverse and sigmoid sinus }\end{array}$ & $\begin{array}{l}\text { Acute venous infarct in right thala- } \\
\text { mus, hippocampus }\end{array}$ \\
\hline 9. & 24 & Male & Headache, vomiting & $\begin{array}{l}\text { Vein of Galen, internal cerebral } \\
\text { veins, inferior sagittal, trans- } \\
\text { verse and straight sinus }\end{array}$ & $\begin{array}{l}\text { Venous infarct in bilateral thalamus } \\
\text { with hemorrhage in left thalamus }\end{array}$ \\
\hline 10. & 58 & Male & Headache, seizures & $\begin{array}{l}\text { Vein of Galen, internal cerebral } \\
\text { vein, straight sinus }\end{array}$ & $\begin{array}{l}\text { Right basal ganglia hemorrhagic } \\
\text { infarct }\end{array}$ \\
\hline 11. & 38 & Male & Headache & $\begin{array}{l}\text { Left transverse and sigmoid } \\
\text { sinus }\end{array}$ & $\begin{array}{l}\text { Left temporal lobe hemorrhagic } \\
\text { infarct }\end{array}$ \\
\hline 12. & 30 & Male & Seizures & $\begin{array}{l}\text { Vein of Galen, straight sinus, } \\
\text { superior sagittal sinus, trans- } \\
\text { verse and sigmoid sinus }\end{array}$ & Acute infarct in left basal ganglia \\
\hline
\end{tabular}

\section{Results}

The mean age of 12 patients was $32.25 \pm 11.42$ yrs. There was a clear male preponderance with nine males and three female patients. As reported in - Table 1, most of the patients (91.66\%) presented with headache, followed by seizures (33.33\%) and visual disturbances (16.66\%). All the patients had features of raised intracranial pressure (ICP), manifesting

Table 2 Risk factors for cerebral venous thrombosis

\begin{tabular}{|l|l|}
\hline Condition/risk factor & Percentage \\
\hline Hyperhomocysteinemia & 50 \\
\hline $\begin{array}{l}\text { Antithrombin III, protein s deficiency, } \\
\text { hyperhomocysteinemia }\end{array}$ & 8.33 \\
\hline Polycythemia & 8.33 \\
\hline Oral contraceptives & 8.33 \\
\hline Iron deficiency anemia & 8.33 \\
\hline Puerperium & 8.33 \\
\hline Unknown & 8.33 \\
\hline
\end{tabular}

as headache with vomiting (33.33\%) or with drowsiness (16.66\%)

All patients underwent brain imaging with MRI along with venogram, and the final diagnosis was based on evidence of parenchymal involvement along with thrombosis of deep cerebral veins. Nine out of 12 patients (75\%) had hemorrhagic infarctions (-Figs. 1, 2). Most patients had involvement of the thalamus, temporal lobe or basal ganglia, while a single patient had bilateral cerebellar hemorrhage. MRI venogram showed diffuse involvement of the deep venous system, with internal cerebral vein and/or vein of Galen involved in all patients (-Fig. 3 ).

Most patients (91.66\%) had identifiable risk factors for CVT. Hypercoagulability was seen two-thirds of the patients, with hyperhomocysteinemia (50\%) being the most common cause ( - Table 2 ).

Except for one, all patients were managed conservatively. The patient with bilateral cerebellar hemorrhage underwent decompressive craniectomy. All the patients had a baseline modified Rankin scale (mRS) score of 3 to 4 (at 


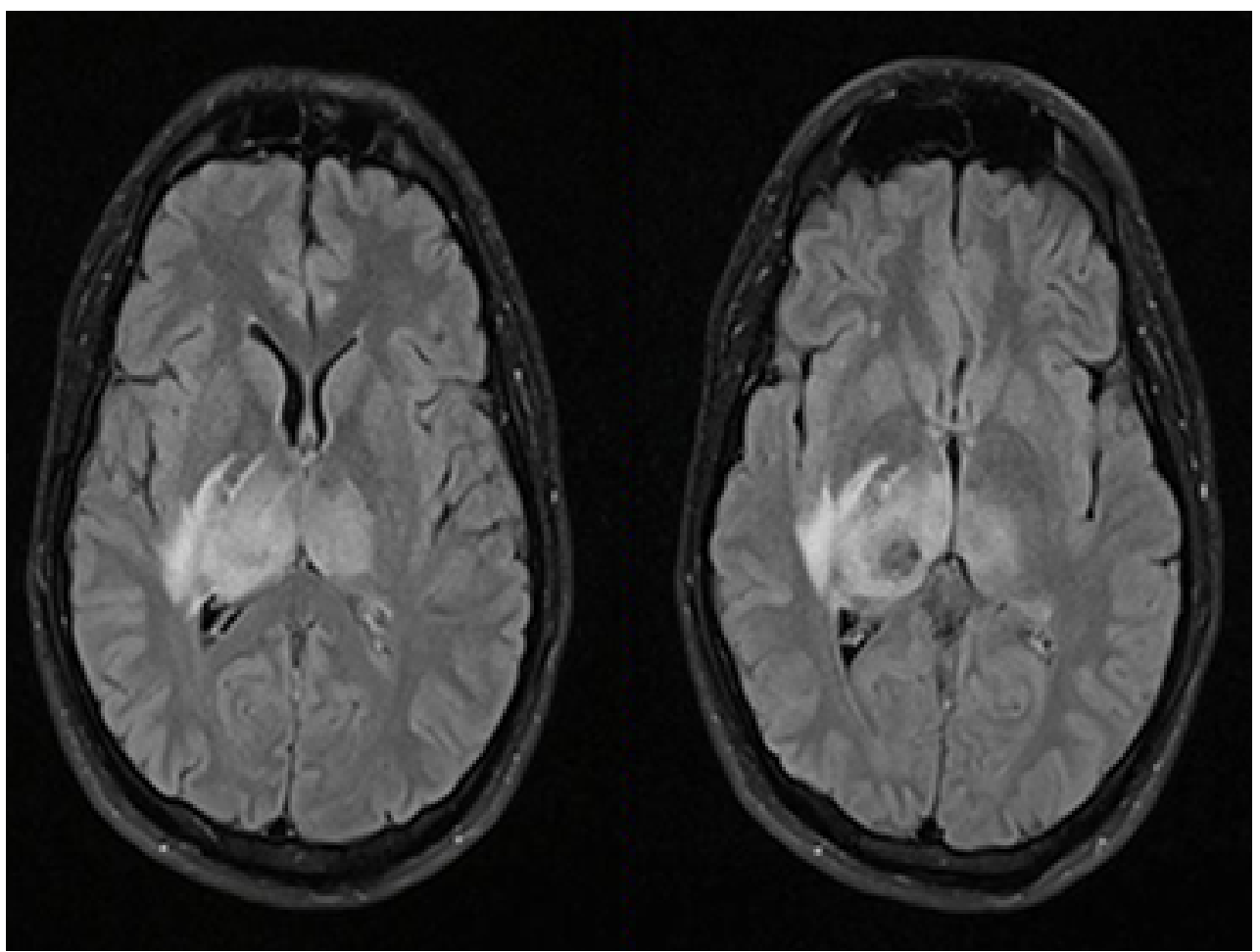

Fig. 1 MRI brain: fluid attenuated inversion recovery (FLAIR) sequence, axial cuts, showing bilateral asymmetrical hyperintensity (right > left) in thalamus with hypointense signal within the right thalamus (patient 2).

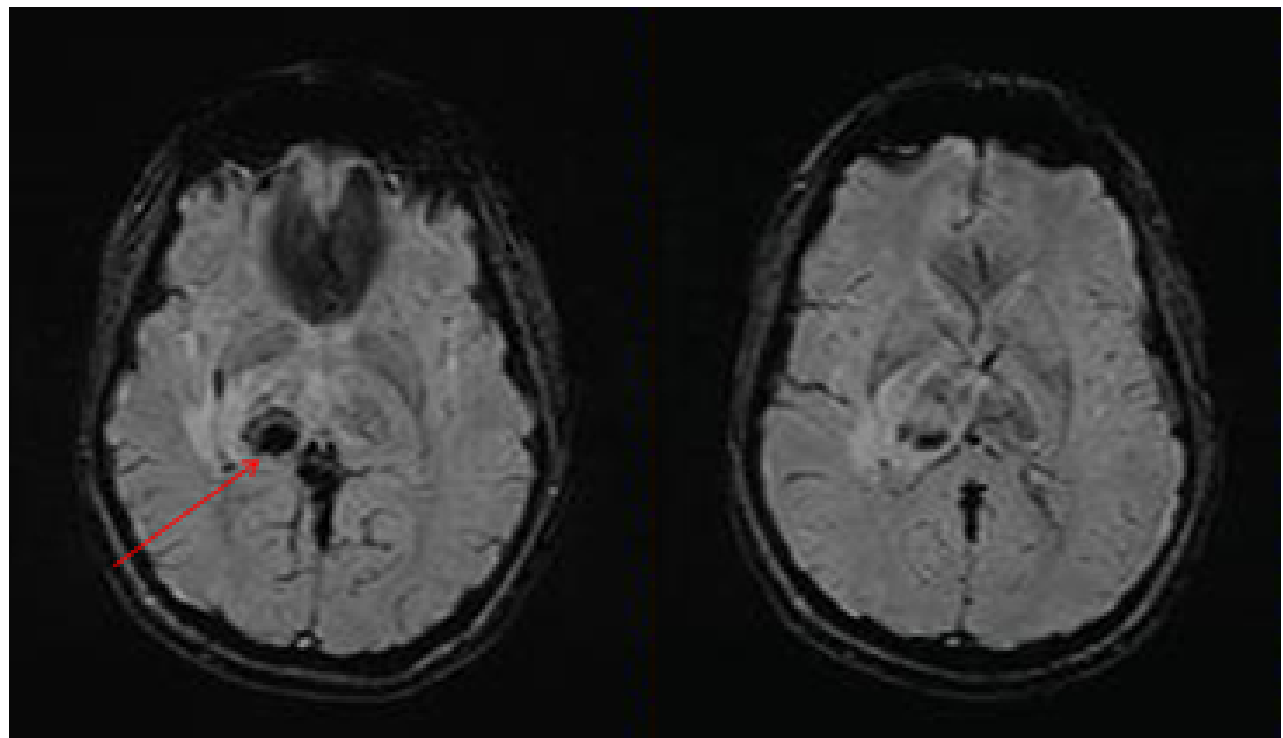

Fig. 2 MRI brain: susceptibility-weighted imaging (SWI) sequence, axial cuts, showing blooming in right thalamus suggestive of hemorrhage (patient 2).

the time of admission), which improved to a score of 0 to 1 in all patients at 3 months follow-up.

\section{Discussion}

The cerebral venous drainage occurs mainly through two systems, the superficial or cortical and the deep or subependymal venous systems. Blood from brain parenchyma drains into the dural sinuses: superior sagittal sinus, inferior sagittal sinus, lateral sinus, cavernous sinus and straight sinus, which then drain into the internal jugular vein (IJV), which finally open into the right ventricle of the heart.

The deep cerebral venous system consists of paired internal cerebral veins, which join the basal veins of Rosenthal to form the great cerebral vein (of Galen). The great cerebral vein joins the inferior sagittal sinus to form the straight sinus. ${ }^{8}$ The deep venous system drains the thalami, septum pellucidum, basal ganglia, upper brainstem, and the deep white matter 


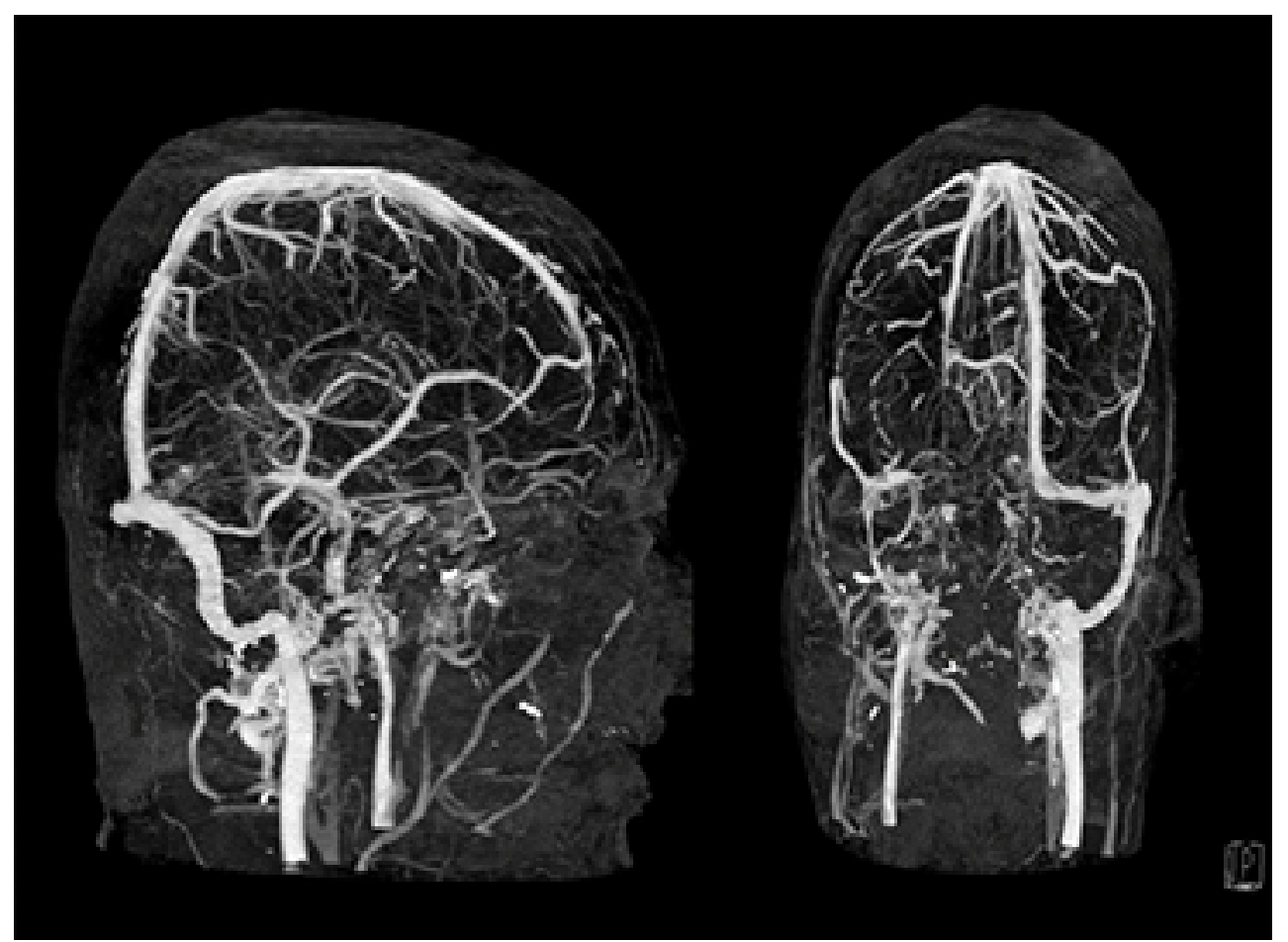

Fig. 3 MRI venogram, time-of-flight (TOF) images showing involvement of vein of Galen, straight sinus, transverse sinus and sigmoid sinus on the right side (patient 2).

of the parietal, temporal, and frontal lobes. ${ }^{9}$ Thus, deep CVT should be considered in any patient with subacute neurological deterioration and bilateral thalamic involvement.

The presence of extensive anastomoses between cortical veins makes the venous territories less well-defined than the arterial ones and also allows for the development of collateral circulation in the event of an occlusion in the venous tree. Development of collateral circulation permits a significant degree of compensation in the early stages of venous thrombosis. CVT commonly affects the superior sagittal sinus (72\%) and the lateral sinuses (70\%). In about one-third of cases, more than one sinus may be involved..$^{10}$ In a further 30 to $40 \%$, both dural venous sinuses as well as cerebral or cerebellar veins are involved. ${ }^{11}$ Deep CVT has been reported in only $10.9 \%$ of all CVT cases. ${ }^{3}$

Venous thrombosis a continuous process in which there is an imbalance between the prothrombotic and thrombolytic processes, leading to slow progressive growth of thrombus with time. ${ }^{12}$ Along with extensive collateralization of the venous vessels, this slow growth of thrombus explains the gradual onset of symptoms of CVT, frequently over weeks or months, in contrast to an abrupt onset in cases of arterial occlusions. ${ }^{12,13}$

The imbalance between prothrombotic and fibrinolytic processes occurs due to changes in blood stasis, vessel wall abnormalities, and hypercoagulability (Virchow's triad). Obstruction of the cerebral venous system leads to increased venous pressure, reduced capillary perfusion, and locally increased cerebral blood volume. Initially, this is compensated by the dilatation of cerebral veins and the development of collateral vessels, but persistent elevation of venous pressure leads to vasogenic edema (due to blood-brain barrier [BBB] disruption) and decreased cerebral perfusion pressure and cerebral blood flow, culminating in tissue infarction. Eventually, both cytotoxic and vasogenic edema occur. ${ }^{13}$

Cerebral venous sinus thrombosis can also block cerebrospinal fluid (CSF) absorption through the arachnoid villi, leading to raised ICP. All the above-mentioned pathophysiological changes cause the typical focal neurological symptoms and signs of CVT, which depend on the following: the territory of the brain involved, the acuity of the occlusion (sudden or gradual), the degree of collateralization, and the degree of associated tissue loss. The slow growth of the thrombus and collateralization of venous vessels probably accounts for the often gradual onset of symptoms in contrast to arterial strokes.

Important and common risk factors for CVT include estrogen-containing oral contraceptive pills, prothrombotic (hypercoagulable) conditions (may be genetic or acquired thrombophilia), pregnancy and puerperium, infections and malignancy. ${ }^{14}$

The International Study on Cerebral Vein and Dural Sinus Thrombosis (ISCVT) found that up to $85 \%$ of adult patients have at least one risk factor, with the most common being the use of oral contraceptive pills, followed by the presence of a prothrombotic state. ${ }^{3}$ In our study, the most common risk factor was presence of hypercoagulable state.

CVT symptomatology ranges from minor to life-threatening, depending on the sinuses and/or veins involved, the extent of brain parenchymal injury, chronicity of occlusion, and the effect on ICP. Thrombosis of the deep veins (internal cerebral veins, basal veins of Rosenthal, vein 
of Galen, straight sinus) often causes edema of bilateral thalami, as was seen in $41.66 \%$ of our study cohort. Thalamic involvement can cause mental status alteration, reduced awareness, coma and gaze palsies, making it a challenging diagnosis without appropriate neuroimaging.

Headache is the most common presenting symptom of CVT described in literature (70-90\% cases), and the same was observed in our study cohort (91.66\%). Headache may be secondary to raised ICP or brain infarction. Other features of raised ICP like vomiting, papilledema, and altered sensorium are also commonly encountered..$^{15}$

Unfortunately, CVT-related headache does not have specific diagnostic features, although it is usually progressive in onset (hours or days). Less often, thunderclap headache can be the first symptom, presumably related to subarachnoid bleeding. ${ }^{16}$

Stroke-like focal neurological symptoms can occur in patients with CVT. In the VENOST study, Duman et al studied 1144 CVT patients and found brain infarction in $36.4 \%$, hemorrhagic transformation in $17.3 \%$, and intraparenchymal hemorrhage in $3.8 \%$ patients. ${ }^{17}$ In our study, $66.66 \%$ of patients had hemorrhagic infarction.

Seizures often occur secondary to disturbances in BBB with edema in the presence of viable cortical neurons and supporting cells. Seizures can be focal, unilateral or bilateral, and can also secondarily generalize. In ISCVT, seizures were present in $40 \%$ of study subjects, ${ }^{3}$ compared to $33.33 \%$ in our study.

Visual disturbances may occur due to (1) raised ICP as a result of venous thrombosis (without venous infarcts, resulting in a benign intracranial hypertension-like presentation), (2) venous infarction involving the occipital cortex, (3) raised ICP following the development of a secondary dural arteriovenous (AV) fistula, and (4) arterial occipital infarcts due to posterior cerebral artery compression, secondary to herniation in large venous infarcts. ${ }^{18}$ Visual disturbances were seen in two $(16.66 \%)$ of our study subjects.

Three of the 12 patients had unilateral thalamic involvement, which is relatively rare in deep CVT. More commonly seen is bilateral thalamic involvement, occurring due to symmetrical drainage. Very few cases of deep CVT with unilateral thalamic involvement are reported in literature. Left thalamus is more commonly involved, which may be attributed to it being a more common anatomical variant or perhaps due to lesser clinical manifestations of nondominant side. ${ }^{19}$

MRI is the most sensitive modality for diagnosing parenchymal lesions, edema, and ruling out other diagnostic dilemmas. CVT is suspected when the area of infarction crosses arterial boundaries or is atypical in location. CT or MRI venogram is indicated if the initial screening MRI or CT scans are inconclusive. Digital subtraction angiography (DSA) is advised if there is parenchymal involvement but CT and/or MRI venogram is inconclusive. On brain imaging, typical findings of deep CVT include bilateral edematous thalami with potentially superimposed venous infarction and haemorrhage, although the findings may be markedly asymmetric or unilateral. ${ }^{20}$ For unknown reasons, in cases of asymmetric
CVT, the right side is more often involved than the left. The same was seen in three of our patients.

Prognosis of CVT is variable. According to the prognostic CVT score, proposed by Ferro et al, involvement of deep cerebral venous system (deep CVT) is a poor prognostic factor. ${ }^{21}$ However, in our cohort, patients had a favorable outcome. mRS scores of all patients improved during follow-up. One of the probable reasons for the better outcome is that all patients presenting with recent onset headache at our institution underwent neuroimaging (preferable with MRI brain + venogram), resulting in to early diagnosis and prompt treatment. Unilateral deep CVT seen in our cohort may also contribute to better outcomes, compared to bilateral deep CVT, which is more commonly reported in literature.

\section{Conclusion}

To date, very few case series of deep CVT have been reported. Our cohort highlights the importance of having a high degree of suspicion of CVT, having an early diagnosis and prompt initiation of treatment, which helps in reducing the morbidity and mortality. In cases of unilateral infarctions, a strong index of suspicion is needed for the diagnosis of deep CVT.

\section{Authors' Contributions}

S.G., D.G. and P.T.A contributed in writing, review, and editing; D.G. and P.R. in conceptualization and investigation; P.R. and A.M. in methodology; D.G. P.R. and M.J. in formal analysis; and R.S. provided supervisory support.

\section{Ethical Approval}

The study is approved by institutional review board (No 08/2018).

\section{Funding}

None.

\section{Conflict of Interest}

None declared.

\section{References}

1 Stam J. Thrombosis of the cerebral veins and sinuses. N Engl J Med 2005;352(17):1791-1798

2 Bousser MG, Ferro JM. Cerebral venous thrombosis: an update. Lancet Neurol 2007;6(2):162-170

3 Ferro JM, Canhão P, Stam J, Bousser MG, Barinagarrementeria F; ISCVT Investigators. Prognosis of cerebral vein and dural sinus thrombosis: results of the International Study on Cerebral Vein and Dural Sinus Thrombosis (ISCVT) Stroke 2004;35(3):664-670

4 Coutinho JM, Ferro JM, Canhão P, et al. Cerebral venous and sinus thrombosis in women. Stroke 2009;40(7):2356-2361

5 Janghorbani M, Zare M, Saadatnia M, Mousavi SA, Mojarrad M, Asgari E. Cerebral vein and dural sinus thrombosis in adults in Isfahan, Iran: frequency and seasonal variation. Acta Neurol Scand 2008;117(2):117-121

6 Saposnik G, Barinagarrementeria F, Brown RDJr, et al; American Heart Association Stroke Council and the Council on Epidemiology and Prevention. Diagnosis and management of cerebral venous thrombosis: a statement for healthcare 
professionals from the American Heart Association/American Stroke Association. Stroke 2011;42(4):1158-1192

7 Canhão P, Ferro JM, Lindgren AG, Bousser MG, Stam J, Barinagarrementeria F; ISCVT Investigators. Causes and predictors of death in cerebral venous thrombosis. Stroke 2005;36(8):1720-1725

8 van den Bergh WM, van der Schaaf I, van Gijn J. The spectrum of presentations of venous infarction caused by deep cerebral vein thrombosis. Neurology 2005;65(2):192-196

9 Dmytriw AA, Song JSA, Yu E, Poon CS. Cerebral venous thrombosis: state of the art diagnosis and management. Neuroradiology 2018;60(7):669-685

10 Bousser MG, Barnett HJM, Stroke: Pathophysiology, Diagnosis, and Management. 2nd ed. New York: Churchill Livingstone; 1992 517-537

11 Ameri A, Bousser MG. Cerebral venous thrombosis. Neurol Clin 1992;10(1):87-111

12 Villringer A, Mehraein S, Einhäupl KM. Pathophysiological aspects of cerebral sinus venous thrombosis (SVT) J Neuroradiol 1994;21(2):72-80

13 Röther J, Waggie K, van Bruggen $\mathrm{N}$, de Crespigny AJ, Moseley ME. Experimental cerebral venous thrombosis: evaluation using magnetic resonance imaging. J Cereb Blood Flow Metab 1996;16(6):1353-1361

14 Gulati D, Strbian D, Sundararajan S. Cerebral venous thrombosis: diagnosis and management. Stroke 2014;45(2):e16-e18
15 Cumurciuc R, Crassard I, Sarov M, Valade D, Bousser MG. Headache as the only neurological sign of cerebral venous thrombosis: a series of 17 cases. J Neurol Neurosurg Psychiatry 2005;76(8):1084-1087

16 de Bruijn SF, Stam J, Kappelle LJ; CVST Study Group. Thunderclap headache as first symptom of cerebral venous sinus thrombosis. Lancet 1996;348(9042) :1623-1625

17 Duman T, Uluduz D, Midi I, et al. VENOST Study Group. A multicenter Study of 1144 patients with cerebral venous thrombosis: The VENOST Study. J Stroke Cerebrovasc Dis 2017;26(8):1848-1857

18 Aaron S, Arthur A, Prabakhar AT, et al. Spectrum of visual impairment in cerebral venous thrombosis: Importance of tailoring therapies based on pathophysiology. Ann Indian Acad Neurol 2017;20(3):294-301

19 Küker W, Schmidt F, Friese S, Block F, Weller M. Unilateral thalamic edema in internal cerebral venous thrombosis: is it mostly left? Cerebrovasc Dis 2001;12(4):341-345

20 Herrmann KA, Sporer B, Yousry TA. Thrombosis of the internal cerebral vein associated with transient unilateral thalamic edema: a case report and review of the literature. AJNR Am J Neuroradiol 2004;25(8):1351-1355

21 Ferro JM, Bacelar-Nicolau H, Rodrigues T, et al. ISCVT and VENOPORT investigators. Risk score to predict the outcome of patients with cerebral vein and dural sinus thrombosis. Cerebrovasc Dis 2009;28(1):39-44 